\title{
Effect of Esmolol hydrochloride on attenuation of stress response during laryngoscopy and intubation in ear, nose and throat (ENT) procedures
}

\author{
Tamaskar $\mathrm{A}^{1}$, Bhargava $\mathrm{S}^{2}$, Rao $\mathrm{M}^{3}$, Bhargava $\mathrm{S}^{4}$, Singh $\mathrm{M}^{5}$ \\ ${ }^{1}$ Dr Aparna Tamaskar, Associate Professor, ${ }^{2}$ Dr Sumit Bhargava, Associate Professor, ${ }^{3}$ Dr Madhumita Rao, Professor, \\ ${ }^{4}$ Dr Sudip Bhargava, Senior Resident Anesthesiology, ${ }^{5}$ Dr Manorama, Singh, Professor and Head, All are affiliated with, \\ L.N. Medical College, Kolar Road, Bhopal, MP, India
}

Address for Correspondence: Dr. Aparna Tamaskar, Department of Anesthesiology, Block A3, L.N. Medical College \& J.K. Hospital Campus, Kolar Road, Bhopal (M.P.) India, Email: drshirishtamaskar@yahoo.com

\begin{abstract}
Introduction: Various techniques and pharmacologic interventions have come in practice to blunt the hemodynamic responses of laryngoscopy and intubation. Beta blocker Esmolol is the drug used in our study to attenuate the stress response of laryngoscopy and intubation. The aim of our study was to observe the efficacy of Esmolol hydrochloride on cardiovascular responses to laryngoscopy and intubation. Methods: Two groups of 25 patients each were taken as control group and Esmolol group and Esmolol $1.5 \mathrm{mgs}$ per $\mathrm{kg}$ IV as bolus dose was administered to Esmolol group 3 minutes prior to induction of anaesthesia followed by laryngoscopy and intubation. The vital parameters were recorded every minute for five minutes Results: There were no significant differences in the basal parameters in both the groups before giving Esmolol and with respect to age, sex and ASA grading. There was significant reduction in heart rate (6.4 $\%)$ at the time of induction as compared to rise of heart rate $(15.16 \%)$ in control group. This was highly significant. Same way - there was fall in systolic blood pressure (7.69\%) in esmolol group in comparison to a rise of $14.28 \%$ in control group. Diastolic blood pressure in esmolol group showed a fall of $2.9 \%$ as compared to a rise of $21.2 \%$ in control group. The RPP was found to decrease by $13.1 \%$ in esmolol group in comparison to a rise of $31.2 \%$ in control group which was also highly statistically significant. Conclusion: Esmolol hydrochloride is proved to be a very effective drug, ultrashort acting rapid onset and offset of action, easily titrable, so highly useful in reducing the stress response of laryngoscopy and intubation.
\end{abstract}

Keywords: Hemodynamic Response, Esmolol, Heart Rate and Blood Pressure.

\section{Introduction}

During laryngoscopy and intubation pathophysiological stress responses (cardio-respiratory) are immediate and often unavoidable even in skilled hands. The mechanical stimulation of four different areas of upper respiratory tract viz. nose, epipharynx, laryngopharynx and the tracheobronchial tree induces reflex cardiovascular responses [1]. These stress responses are seen because of stimulation of epipharynx and laryngopharynx and least with tracheobronchial stimulation. The sensory afferents from the epipharynx and laryngopharynx are carried by glossopharyngeal

Manuscript received: $20^{\text {th }}$ Nov 2015

Reviewed: $1^{\text {st }}$ Dec 2015

Author Corrected: $10^{\text {th }}$ Dec 2015

Accepted for Publication: $23^{\text {rd }}$ Dec 2015 nerve, while trigeminal and vagus nerves carry sensations from tracheobronchial tree. This results in enhanced neural activity in the cervical sympathetic afferent fibers. These afferent fibers activate the vasomotor centre which ends in reflex cardiovascular responses in the form of tachycardia, hypertension and cardiac dysrrhythmias and laryngobronchialspasm. Laryngovagal stimulation causes abradycardia, laryngosympathetic stimulation leads to hypertension and tachycardia. Laryngospinal stimulation leads to hypotension and splanchnic reflexes. The aim is to protect the heart from noxious stimulation arising as a result of laryngoscopy and intubation. The normal patients usually tolerate this increased sympathetic response but patients having valvular heart disease, 
coronary artery disease, aortic aneurysms, recent myocardial infarction and cerebral aneurysms or intracranial hypertension require careful hemodynamic control during laryngoscopy, intubation, extubation, skin incision and surgical manipulations. The rise in heart rate, systolic and diastolic blood pressure, mean arterial pressure are highly undesirable in such patients. Beta-blockers are widely used to treat tachycardia, hypertension and arrhythmias resulting from $\mathrm{p}$ adrenergic stimulation, thereby reducing a patient's risk of developing myocardial ischemia, infarction and arrhythmia. The prolonged action of currently available Beta-blockers is not desirable in cardiac patients. Esmolol hydrochloride Esmolol hydrochloride was evaluated as the preferable agent to attenuate the stress response due to laryngoscopy and intubation for the following reasons.

1. It is a cardioselective $\beta-1$ antagonist, without any intrinsic sympathomimetic effect or membrane stabilising property.

2. Its lack of action on $\beta-2$ receptors, makes it the $\beta$ blocker of choice in patients having bronchial asthma.

3. Its onset of action being within a minute it can produce the required haemodynamic stability soon after its administration.

4. Its metabolism is not influenced by renal or hepatic function. It is rapidly hydrolysed by cytoplasmic esterases in hepatic cells and RBG. Patients with deficient plasma cholinesterase do not show prolonged effect of Esmolol.

5. Its action is similar to other p-blockers. Decreasing cardiac output by reducing heart rate and force of contraction. Cardiac work and oxygen consumption are reduced. These qualities are beneficial in angina patients and hypertensives.

6. Its peak haemodynamic effects are produced within 6-10 min of administration.

7. It is an ultrashort acting p-blocker with a short elimination half life of approximately $9 \mathrm{~min}$ (range 5-16 min). Midazolam took about $10 \mathrm{~min}$. and diazepam even longer .

\section{Methods}

Fifty patients belonging to ASA grade I \& II between 20-50 years it participated in the present study. They were scheduled for elective surgical procedures requiring endotracheal anaesthesia.

Patients were randomly divided into 2 groups of twenty five each

Group I - Control group

Group II - Patients receiving Esmolol

All the selected patients underwent a thorough clinical systemic and physical examination including evaluation of the airway. Patient's age and weight was noted. Blood haemogram, Urine examination - Routine \& Microscopic, Blood Sugar, Blood Urea, X-Ray Chest, EGG were done.

The patients in whom difficulty in tracheal intubation was anticipated, Patients with AV conduction blocks, CCF, Patients with diabetes mellitus, Cardiac arrhythmias, Bronchial asthma, Use of Beta-blockers within $24 \mathrm{hrs}$ preceding surgery were excluded from this study.After transfering the patients to the operating room, an IV line was established with an $18 \mathrm{G}$ cannula. Multichannel monitor was used to observe all the clinical parameters like heart rate, systolic, diastolic, mean arterial pressure, ECG - Lead II, $\mathrm{Sp}_{2}$, $\mathrm{ETCO}_{2}$.Preoxygenation with $100 \% \mathrm{O}_{2}$ was done for 3 minutes. This was followed by IV Esmolol $1.5 \mathrm{mg} / \mathrm{kg}$ as a bolus dose over a period of 1 minute. After the Esmolol injection, induction of anesthesia was carried out with IV Propofol $2-2.5 \mathrm{mgs} / \mathrm{kg}$ till the eye-lash reflex was lost. Inj. Atracurium $0.5 \mathrm{mgs} / \mathrm{kg}$ was given intravenously. The oxygenation was maintained with intermittent positive pressure ventilation. After observing complete jaw relaxation, laryngoscopy was done and intubation was carried out with appropriate endotracheal tube.

The endotracheal tube was connected to closed circuit system and IPPV commenced. Anaesthesia was maintained with $\mathrm{O}_{2}$ and $\mathrm{N}_{2} \mathrm{O} 50 \%$ each. No muscle relaxant was given in first 5 minutes following intubation. No inhalational agent or any other drug was administered in the above said period. No surgical manipulation was permitted during this period Meanwhile all the required parameters viz. heart rate, systolic blood pressure, diastolic blood pressure, mean arterial pressure and rate pressure product were noted every minute following intubation.

\section{Results}


There was no significant difference in basal parameters - heart rate, systolic, diastolic, mean arterial pressures and rate pressure product observed in the two groups.

With respect to age, sex and ASA Grading, the control as well as Esmolol group were similar and there was no significant difference seen. The Esmolol group showed a reduction of $6.4 \%$ in heart rate at the time of induction (88.64 \pm 12.4 to $82.96+10.72)$, as compared to a rise of $15.16 \%$ in the control group $(88.6 \pm 11.79$ to $102.04 \pm 10.81)$. This was clinically as well as statistically highly significant $(\mathrm{p}<0.001)$.

Table 1: The Means \pm SD of the bases heart rate (HR) in beats / minute, systolic blood pressure (SAP), diastolic blood pressure (DAP) and mean arterial pressure (MAP) in mmHg of the patients in each of the two groups

\begin{tabular}{|l|l|l|l|}
\hline Haemodynamic Variable & & Control Group & Esmolol Group \\
\hline \multirow{2}{*}{ Heart Rate } & Mean & 88.6 & 88.64 \\
\cline { 2 - 4 } & + SD & 11.79 & 12.4 \\
\hline \multirow{2}{*}{ SAP } & Mean & 121.92 & 120.72 \\
\cline { 2 - 4 } & + SD & 9.7 & 9.36 \\
\hline \multirow{2}{*}{ DAP } & Mean & 74.72 & 75.44 \\
\cline { 2 - 4 } & + SD & 4.86 & 4.95 \\
\hline \multirow{2}{*}{ MAP } & Mean & 90.08 & 90.52 \\
\cline { 2 - 4 } & + SD & 3.91 & 4.91 \\
\hline \multirow{2}{*}{ RPP } & Mean & 10769.84 & 10698 \\
\cline { 2 - 4 } & + SD & 1477.41 & 1687.63 \\
\hline
\end{tabular}

Table 2: Mean \pm SD of heart rate (HR) IN beats/minutes recorded at different time intervals in both the groups

\begin{tabular}{|c|c|c|c|c|c|c|}
\hline Haemodynamic Variable & & Contro & & Esmol & & 'P' Value \\
\hline Dost 1 & Mean & 88.6 & 0 & 88.64 & 0 & $>005$ \\
\hline Basal Heart Rate & $+\mathrm{SD}$ & 11.79 & 0 & 12.4 & 0 & $>0.05$ \\
\hline At Induction & Mean & 102.04 & 15.1607 & 82.96 & 6407 & $<\rho \Omega O 1$ \\
\hline At induction & $+\mathrm{SD}$ & 10.81 & $15.10 \%$ & 10.72 & $-0.4 \%$ & $<0.001$ \\
\hline & Mean & 114.72 & & 82.8 & & \\
\hline 1 Min & $+\mathrm{SD}$ & 9.56 & $29.48 \%$ & 11.7 & $-6.58 \%$ & $<0.001$ \\
\hline O M. & Mean & 112.08 & & 83.36 & & ( 0001 \\
\hline 2 Min & $+\mathrm{SD}$ & 8.05 & $26.5 \%$ & 11.75 & $-5.94 \%$ & $<0.001$ \\
\hline & Mean & 110.56 & & 85.76 & & \\
\hline 3 Min & $+\mathrm{SD}$ & 7.77 & $24.78 \%$ & 11.87 & $-3.24 \%$ & $<0.001$ \\
\hline & Mean & 109.6 & & 86.12 & 07 & 01 \\
\hline 4 Min & $+\mathrm{SD}$ & 7.63 & $23.7 \%$ & 11.92 & $-2.84 \%$ & $<0.001$ \\
\hline & Mean & 108.24 & & 88.12 & & \\
\hline 5 Min & $+\mathrm{SD}$ & 7.85 & $22.16 \%$ & 12.68 & $-0.58 \%$ & $<0.001$ \\
\hline
\end{tabular}

There was a fall of $7.69 \%$ in systolic blood pressure $(120.72 \pm 9.36$ to $111.44 \pm 9.7)$ in the Esmolol group in comparison to a peak of $14.28 \%(121.92 \pm 9.7$ to $139.2 \pm 10)$ in the control group. This observation is also proved to be clinically as well as statistically highly significant. 
Tabl 3: Mean \pm SD standard deviation of systolic blood pressure in mmHg recorded at different time intervals

\begin{tabular}{|c|c|c|c|c|c|c|}
\hline \multirow{3}{*}{$\begin{array}{l}\text { Haemodynamic Variable } \\
\text { Basal SAP }\end{array}$} & & \multicolumn{2}{|c|}{ Control Group } & \multicolumn{2}{|c|}{ Esmolol Group } & \multirow{3}{*}{$\begin{array}{l}\text { 'P' Value } \\
>0.05\end{array}$} \\
\hline & Mean & 121.92 & \multirow{2}{*}{0} & 120.72 & \multirow{2}{*}{0} & \\
\hline & $+\mathrm{SD}$ & 9.7 & & 9.36 & & \\
\hline \multirow{2}{*}{ At Induction } & Mean & 139.2 & \multirow{2}{*}{$14.28 \%$} & 111.44 & \multirow{2}{*}{$-7.69 \%$} & \multirow{2}{*}{$<0.001$} \\
\hline & $+\mathrm{SD}$ & 10 & & 9.7 & & \\
\hline \multirow{2}{*}{$1 \mathrm{Min}$} & Mean & 145.28 & \multirow{2}{*}{$19.46 \%$} & 110.76 & \multirow{2}{*}{$-8.26 \%$} & \multirow{2}{*}{$<0.001$} \\
\hline & $+\mathrm{SD}$ & 8.86 & & 11.08 & & \\
\hline \multirow{2}{*}{$2 \mathrm{Min}$} & Mean & 137.28 & \multirow{2}{*}{$12.69 \%$} & 109.84 & \multirow{2}{*}{$-9 \% .02 \%$} & \multirow{2}{*}{$<0.001$} \\
\hline & $+\mathrm{SD}$ & 9.07 & & 11.34 & & \\
\hline \multirow{2}{*}{$3 \mathrm{Min}$} & Mean & 134.08 & \multirow{2}{*}{$10 \%$} & 108.6 & \multirow{2}{*}{$-10.04 \%$} & \multirow{2}{*}{$<0.001$} \\
\hline & $+\mathrm{SD}$ & 8.19 & & 11.17 & & \\
\hline \multirow{2}{*}{4 Min } & Mean & 131.84 & \multirow{2}{*}{$8.2 \%$} & 108.08 & \multirow{2}{*}{$-10.48 \%$} & \multirow{2}{*}{$<0.001$} \\
\hline & $+\mathrm{SD}$ & 7.85 & & 10.43 & & \\
\hline \multirow{2}{*}{$5 \mathrm{Min}$} & Mean & 129.44 & \multirow{2}{*}{$6.2 \%$} & 106.24 & \multirow{2}{*}{$-12 \%$} & \multirow{2}{*}{$<0.001$} \\
\hline & $+\mathrm{SD}$ & 7.69 & & 11.28 & & \\
\hline
\end{tabular}

Table-4: Mean \pm SD of diastolic blood pressure (DBP) in mmhg recorded at different time intervals in both the groups

\begin{tabular}{|c|c|c|c|c|c|c|}
\hline \multirow{3}{*}{$\begin{array}{l}\text { Haemodynamic } \\
\text { Variable } \\
\text { Basal DAP }\end{array}$} & & \multicolumn{2}{|c|}{ Control Group } & \multicolumn{2}{|c|}{ Esmolol Group } & \multirow{3}{*}{$\begin{array}{l}\text { 'P' Value } \\
>0.05\end{array}$} \\
\hline & Mean & 74.72 & \multirow{2}{*}{0} & 75.44 & \multirow{2}{*}{0} & \\
\hline & $+\mathrm{SD}$ & 4.86 & & 4.95 & & \\
\hline \multirow{2}{*}{ At Induction } & Mean & 90.56 & \multirow{2}{*}{$21.2 \%$} & $7 . .4$ & \multirow{2}{*}{$-2.9 \%$} & \multirow{2}{*}{$<0.001$} \\
\hline & $+\mathrm{SD}$ & 5.58 & & 5.28 & & \\
\hline \multirow{2}{*}{$1 \mathrm{Min}$} & Mean & 95.2 & \multirow{2}{*}{$27.5 \%$} & 72.72 & \multirow{2}{*}{$-3.6 \%$} & \multirow{2}{*}{$<0.001$} \\
\hline & $+\mathrm{SD}$ & 4.47 & & 5.91 & & \\
\hline \multirow{2}{*}{2 Min } & Mean & 93 & \multirow{2}{*}{$24.5 \%$} & 72.16 & \multirow{2}{*}{$-4.4 \%$} & \multirow{2}{*}{$<0.001$} \\
\hline & $+\mathrm{SD}$ & 4.45 & & 5.32 & & \\
\hline \multirow{2}{*}{3 Min } & Mean & 88.88 & \multirow{2}{*}{$18.9 \%$} & 71.84 & \multirow{2}{*}{$-4.8 \%$} & \multirow{2}{*}{$<0.001$} \\
\hline & $+\mathrm{SD}$ & 4.47 & & 5.38 & & \\
\hline \multirow{2}{*}{4 Min } & Mean & 86.28 & \multirow{2}{*}{$15.5 \%$} & 71.68 & \multirow{2}{*}{$-5 \%$} & \multirow{2}{*}{$<0.001$} \\
\hline & $+\mathrm{SD}$ & 4.61 & & 5.4 & & \\
\hline \multirow{2}{*}{5 Min } & Mean & 84 & \multirow{2}{*}{$12.5 \%$} & 71.76 & \multirow{2}{*}{-4.9} & \multirow{2}{*}{$<0.001$} \\
\hline & $+\mathrm{SD}$ & 4.79 & & 5.36 & & \\
\hline
\end{tabular}

As regards diastolic blood pressure, the esmolol group showed a decrease $2.9 \%$ as compared to a rise of $21.2 \%$ in control group).

Table 5: Mean \pm SD of diastolic blood pressure (DBP) in $\mathbf{m m H g}$ recorded at different time intervals in both the groups

\begin{tabular}{|c|c|c|c|c|c|c|}
\hline \multirow{3}{*}{$\begin{array}{l}\text { Haemodynamic } \\
\text { Variable } \\
\text { Basal DAP }\end{array}$} & & \multicolumn{2}{|c|}{ Control Group } & \multicolumn{2}{|c|}{ Esmolol Group } & \multirow{3}{*}{$\begin{array}{l}\mathbf{P} \text { ' Value } \\
>0.05\end{array}$} \\
\hline & Mean & 74.72 & \multirow{2}{*}{0} & 75.44 & \multirow{2}{*}{0} & \\
\hline & $+\mathrm{SD}$ & 4.86 & & 4.95 & & \\
\hline \multirow{2}{*}{ At Induction } & Mean & 90.56 & \multirow{2}{*}{$21.2 \%$} & $7 . .4$ & \multirow{2}{*}{$-2.9 \%$} & \multirow{2}{*}{$<0.001$} \\
\hline & $+\mathrm{SD}$ & 5.58 & & 5.28 & & \\
\hline \multirow{2}{*}{$1 \mathrm{Min}$} & Mean & 95.2 & \multirow{2}{*}{$27.5 \%$} & 72.72 & \multirow{2}{*}{$-3.6 \%$} & \multirow{2}{*}{$<0.001$} \\
\hline & $+\mathrm{SD}$ & 4.47 & & 5.91 & & \\
\hline
\end{tabular}




\begin{tabular}{|c|c|c|c|c|c|c|}
\hline \multirow{2}{*}{2 Min } & Mean & 93 & \multirow{2}{*}{$24.5 \%$} & 72.16 & \multirow{2}{*}{$-4.4 \%$} & \multirow{2}{*}{$<0.001$} \\
\hline & $+\mathrm{SD}$ & 4.45 & & 5.32 & & \\
\hline \multirow{2}{*}{3 Min } & Mean & 88.88 & \multirow{2}{*}{$18.9 \%$} & 71.84 & \multirow{2}{*}{$-4.8 \%$} & \multirow{2}{*}{$<0.001$} \\
\hline & $+\mathrm{SD}$ & 4.47 & & 5.38 & & \\
\hline \multirow{2}{*}{4 Min } & Mean & 86.28 & \multirow{2}{*}{$15.5 \%$} & 71.68 & \multirow{2}{*}{$-5 \%$} & \multirow{2}{*}{$<0.001$} \\
\hline & $+\mathrm{SD}$ & 4.61 & & 5.4 & & \\
\hline \multirow{2}{*}{$5 \mathrm{Min}$} & Mean & 84 & \multirow{2}{*}{$12.5 \%$} & 71.76 & \multirow{2}{*}{-4.9} & \multirow{2}{*}{$<0.001$} \\
\hline & $+\mathrm{SD}$ & 4.79 & & 5.36 & & \\
\hline
\end{tabular}

Table 6: Means and \pm SD of mean arterial pressure in $\mathbf{m m H g}$ recorded at different time intervals in both the groups

\begin{tabular}{|c|c|c|c|c|c|c|}
\hline \multirow{3}{*}{$\begin{array}{l}\text { Haemodynamic } \\
\text { Variable } \\
\text { Basal MAP }\end{array}$} & & \multicolumn{2}{|c|}{ Control Group } & \multicolumn{2}{|c|}{ Esmolol Group } & \multirow{3}{*}{$\begin{array}{l}\mathbf{P} \text { ' Value } \\
>0.05\end{array}$} \\
\hline & Mean & 90.08 & \multirow{2}{*}{0} & 90.52 & \multirow{2}{*}{0} & \\
\hline & $+\mathrm{SD}$ & 3.91 & & 4.61 & & \\
\hline \multirow{2}{*}{ At Induction } & Mean & 106.72 & \multirow{2}{*}{$16.64 \%$} & 86.08 & \multirow{2}{*}{$-4.44 \%$} & \multirow{2}{*}{$<0.001$} \\
\hline & $+\mathrm{SD}$ & 7.86 & & 4.91 & & \\
\hline \multirow{2}{*}{$1 \mathrm{Min}$} & Mean & 111.36 & \multirow{2}{*}{$21.28 \%$} & 85.56 & \multirow{2}{*}{$-4.96 \%$} & \multirow{2}{*}{$<0.001$} \\
\hline & $+\mathrm{SD}$ & 4.17 & & 5.16 & & \\
\hline \multirow{2}{*}{$2 \mathrm{Min}$} & Mean & 107.64 & \multirow{2}{*}{$17.56 \%$} & 85 & \multirow{2}{*}{$-5.52 \%$} & \multirow{2}{*}{$<0.001$} \\
\hline & $+\mathrm{SD}$ & 2.99 & & 5.28 & & \\
\hline \multirow{2}{*}{$3 \mathrm{Min}$} & Mean & 104.12 & \multirow{2}{*}{$14.04 \%$} & 84.92 & \multirow{2}{*}{$-5.6 \%$} & \multirow{2}{*}{$<0.001$} \\
\hline & $+\mathrm{SD}$ & 3.95 & & 4.61 & & \\
\hline \multirow{2}{*}{4 Min } & Mean & 102.56 & \multirow{2}{*}{$12.48 \%$} & 81.08 & \multirow{2}{*}{$-9.44 \%$} & \multirow{2}{*}{$<0.001$} \\
\hline & $+\mathrm{SD}$ & 9.4 & & 4.39 & & \\
\hline \multirow{2}{*}{$5 \mathrm{Min}$} & Mean & 98.8 & \multirow{2}{*}{$8.72 \%$} & 82.4 & \multirow{2}{*}{$-8.12 \%$} & \multirow{2}{*}{$<0.001$} \\
\hline & $+\mathrm{SD}$ & 3.91 & & 4.88 & & \\
\hline
\end{tabular}

In the control group mean arterial pressure reached a peak of $18.4 \%$ ( 90.08 to $106.72 \pm 7.86$ ) at the the time of induction while in the esmolol group we observed a fall of $4.9 \%$ ( 90.52 to $86.08 \pm 4.91$ ) at the same time.

Table 7: Means and \pm SD of rate pressure product at different time intervals in both the groups

\begin{tabular}{|c|c|c|c|c|c|c|}
\hline \multirow{3}{*}{$\begin{array}{l}\begin{array}{l}\text { Haemodynamic } \\
\text { Variable }\end{array} \\
\text { Basal RPP }\end{array}$} & & \multicolumn{2}{|c|}{ Control Group } & \multicolumn{2}{|c|}{ Esmolol Group } & \multirow{3}{*}{$\begin{array}{l}\text { 'P' Value } \\
>0.05\end{array}$} \\
\hline & Mean & 10769.84 & \multirow{2}{*}{0} & 10698 & \multirow{2}{*}{0} & \\
\hline & $+\mathrm{SD}$ & 1477.41 & & 1687.63 & & \\
\hline \multirow{2}{*}{ At Induction } & Mean & 14121.44 & \multirow{2}{*}{$31.2 \%$} & 9301.12 & \multirow{2}{*}{$-13.1 \%$} & \multirow{2}{*}{$<0.001$} \\
\hline & $+\mathrm{SD}$ & 1485.11 & & 1377.98 & & \\
\hline \multirow{2}{*}{$1 \mathrm{Min}$} & Mean & 16555.04 & \multirow{2}{*}{$53.7 \%$} & 9171 & \multirow{2}{*}{$-14.3 \%$} & \multirow{2}{*}{$<0.001$} \\
\hline & $+\mathrm{SD}$ & 1483.47 & & 1539.23 & & \\
\hline \multirow{2}{*}{2 Min } & Mean & 15461.12 & \multirow{2}{*}{$43.5 \%$} & 9146.76 & \multirow{2}{*}{$-14.5 \%$} & \multirow{2}{*}{$<0.001$} \\
\hline & $+\mathrm{SD}$ & 1402.17 & & 1513.36 & & \\
\hline \multirow{2}{*}{3 Min } & Mean & 14812.16 & \multirow{2}{*}{$37.5 \%$} & 9302.12 & \multirow{2}{*}{$-13.1 \%$} & \multirow{2}{*}{$<0.001$} \\
\hline & $+\mathrm{SD}$ & 1247.23 & & 1510.49 & & \\
\hline \multirow{2}{*}{4 Min } & Mean & 14345.6 & \multirow{2}{*}{$33.2 \%$} & 9296 & \multirow{2}{*}{$-13.2 \%$} & \multirow{2}{*}{$<0.001$} \\
\hline & $+\mathrm{SD}$ & 1027.57 & & 1471.43 & & \\
\hline \multirow{2}{*}{5 Min } & Mean & 13993.44 & \multirow{2}{*}{$30 \%$} & 9362.88 & \multirow{2}{*}{$-12.5 \%$} & \multirow{2}{*}{$<0.001$} \\
\hline & $+\mathrm{SD}$ & 1111.44 & & 1691.49 & & \\
\hline
\end{tabular}


The rate pressure product was found to fall from 10698 to $9301.12 \pm 1378(13.1 \%)$ in study group and a rise from 10770 to $14121(31.2 \%)$. This was clinically and statistically significant.

\section{Discussion}

The quest for effective blockage of these sympathetic responses led to the use of topical or intravenous lidocaine, vasodilators, $\beta$-adrenergic blockers, narcotics and inhaled anaesthetics. Lidocaine and vasodilators are effective in controlling hypertension but not the heart rate, so provide an incomplete solution to the problem. In the appropriate doses, narcotics like fentanyl control both heart rate and blood pressure responses however complex respiratory depression and truncal rigidity are frequent accompaniments.

Beta-blockers are widely used to treat tachycardia, hypertension and arrhythmias resulting from $\beta$ adrenergic stimulation, thereby reducing a patient's risk of developing myocardial ischaemia, infarction and arrhythmia. However the relatively long duration of action of currently available intravenous $\beta$ - blockers limit their use because of the potential for adverse effects that may not be rapidly reversible in these critically ill patients.

In such critical situations a short acting, titrable, betablocker which can permit precise control over the magnitude and duration of $\beta$-blockage is highly desirable. The effects rapidly dissipate on termination of infusion if the $\beta$ blockage is no longer desired or when adverse reactions develop.

The administration of Esmolol by infusion has been described by a number of authors ${ }^{[2]}$ while infusions are easy to set up, they require additional time and equipment. Bolus doses of Esmolol may circumvent these problems. Recent studies have investigated the use of bolus doses of esmolol for the prevention of postintubation tachycardia and hypertension.

Korenaga et al (1985) studied 22 patients who received an Esmolol infusion of $500 \mu-\mathrm{g} / \mathrm{kg} / \mathrm{min}$ loading dose for 4 minutes before induction with pentothal and 300 $\mu \mathrm{g} / \mathrm{kg} / \mathrm{min}$ for maintenance for 6 additional minute during endotracheal intubation [3]. None of these changes were significantly different from pre-esmolol infusion values. The corresponding pulse rates for controls were $85.2 \pm 4.3, \quad 92.6 \pm 4.6, \quad 111.3 \pm 4.4$, significantly greater in the control group compared to the esmolol treated group $(\mathrm{P}<0.001)$.
Some authors did a comparative study of hemodynamic effects of esmolol with propanolol [4]. They observed a significant fall in heart rate during the infusions of 200$250 \mu \mathrm{g} / \mathrm{kg} / \mathrm{min}$ esmolol. Another study has shown that Esmolol delivered in a bolus of approximately 1.5 $\mathrm{mg} / \mathrm{kg}$ appeared to prevent hypertension and tachycardia [5].

An earlier study concluded that single bolus injection of Esmolol 100-200 mg IV 2 to $3 \mathrm{~min}$. before intubation have limited heart rate and systolic blood pressure responses [6]. A study determined the effectiveness of 100-200 mg preinduction bolus doses of Esmolol 90 seconds prior to laryngoscopy and intubation [7]. They found that heart rate and systolic blood pressure remained lower in the $200 \mathrm{mg}$ group at 30 seconds and 90 seconds after laryngoscopy and intubation for 6 minute 30 seconds. They concluded that a larger dose of Esmolol approximately $3 \mathrm{mg} / \mathrm{kg}$ was required for effective control.

Another study a double blind randomized controlled prospective study comparing esmolol with placebo [7] has shown Patients in the esmolol group had a significant decline in heart rate during the pre-induction period compared with the control group $(\mathrm{p}<0.001)$. Immediately after laryngoscopy though both groups developed similar and significant increases in heart rate $(p<0.001)$ but were less significant in the study group $(\mathrm{p}<0.05)$.

We found mean heart rate at induction in control group was

$(\mathrm{SD} \pm 10.81)$ as compared to basal values of 88.6 $(\mathrm{SD} \pm 11.79)$. While in Esmolol group it decreased from $88.64(\mathrm{SD} \pm 12.4)$ to $82.96(\mathrm{SD} \pm 10.72)(\mathrm{p}<0.05)$ which showed it to be statistically significant.

A 1 minute, the reduction in heart rate in study group was $6.58 \%$ as compared to control group - rise of $29.48 \%$. Similarly at the end of 3 minutes, it was a fall of $3.24 \%$ in study group and a rise of $24.78 \%$ in control group.

At the end of 5 minutes, a decrease in heart rate from basal values of $0.58 \%$ was seen in Esmolol group, in comparison there was still a rise of $22.16 \%$ in control group. Our findings are almost similar to above studies. 
A study observed changes in systolic blood pressure preoperative values of $150.2 \pm 7.8 \mathrm{~mm} \mathrm{Hg}$ changed to $149.4 \pm 6.4$ after esmolol infusion [3]. The corresponding findings in control group were $140.7 \pm 4.5,141.7 \pm 6.4$, $188.8 \pm 8.5,179.7 \pm 8.3$ and $142.7 \pm 8.8$, was significantly greater $(\mathrm{p}<0.01)$ than the esmolol group.

Another study concluded that in the $200 \mathrm{mg}$ esmolol group there was a significant decrease in systolic blood pressure as compared to the placebo, at $0.5 \mathrm{~min}(144 \pm$ 32.1 vs $165 \pm 18.7 \mathrm{~mm} \mathrm{Hg}$ ) and $1.5 \mathrm{~min}$. (154 \pm 25.0 vs $170 \pm 19.5 \mathrm{~mm} \mathrm{Hg}$ ) after intubation [8]. In the Esmolol group, we observed changes in systolic blood pressure, basal value being 102.72 ( $\mathrm{SD} \pm 9.36$ ) and changes were 111.44 (SD \pm 9.7 ) at the time of induction, 110.76 (SD $\pm 11.08)$ at $1 \mathrm{~min}, 108.6(\mathrm{SD}+11.17)$ at $3 \mathrm{~min}$ and 106.24 (SD \pm 11.28$)$ at $5 \mathrm{~min}$. Compared to the control group, the changes seen were from basal value of 121.92 ( $\mathrm{SD} \pm 9.7)$ to $139.2(\mathrm{SD} \pm 10)$ at induction, $145.28(\mathrm{SD} \pm 8.86)$ at $1 \mathrm{~min}, 139.08(\mathrm{SD} \pm 8.19)$ at $3 \mathrm{~min}$ and 129.44 (SD \pm 7.69 ) at $5 \mathrm{~min}$ respectively. It is concluded that the changes were consistent and statistically significant throughout the observed period $(\mathrm{p}<0.05)$. These findings are similar to the changes in systolic blood pressure observed by other authors [9].

In our study, the diastolic blood pressure in the study group observed a fall of $2.9 \%$ at the time of induction, . Later at 1 minute, the diastolic blood pressure had a reduction of $3.6 \%$ in esmolol group compared to control group. At the end of 3 and 5 minutes, the changes in diastolic blood pressure were $71.84 \pm 5.38$ and 71.76 \pm 5.36 in esmolol group. These findings were clinically and statistically significant $(\mathrm{p}<0.05)$ another author also observed similar changes in diastolic blood pressure [7]. Our findings were found to be statistically significant $(\mathrm{p}<0.05)$.

Another author observed rate pressure products were consistently and significantly increased in the control group compared with the study group $(p<0.001)$ [7]. In the esmolol group the rate pressure product exceeded 15,000 in only one patient and this was associated with the only prolonged and difficult laryngoscopy.

A study concluded that rate pressure product in the esmolol group compared to control group was $(13,393$ vs 19,947 beats/min $\mathrm{mmHg})(\mathrm{p}<0.001)$ [9]. In our study, we have found the rate pressure product decreased from 10698 to 9301 at the time of induction, and $9171,9302,9362.88$ respective at 1, 3, 5 minutes after induction. There was a significant fall of $13.1 \%$ at the time of induction in the esmolol group. While the control group observed a rise in rate pressure product from 10767 to $14121,16555,14812.16,3226.6$ at induction, 1, 3 and 5 minutes respectively. The rise in rate pressure product of $31.2 \%$ at the induction time is clinically as well as statistically significant $(\mathrm{p}<0.05)$ as compared to similar findings in study group.

The above study establishes the usefulness of bolus dose of Esmolol $1.5 \mathrm{mg} / \mathrm{kg}$ IV in attenuating the stress response, abolishing tachycardia \& hypertension, cardiac dysrhythmias associated with laryngoscopy and intubation.

\section{Conclusions}

Esmolol hydrochloride, hereby, is proved to be a very effective drug, ultra short acting, rapid onset and offset of action, easily titrable, so highly useful in reducing the stress response due to laryngoscopy and intubation during ENT procedures.

\section{Funding:Nil. Conflict of interest: Nil. Permission for IRB: Yes}

\section{References}

1. WYCOFF CC. Endotracheal intubation: effects on blood pressure and pulse rate. Anesthesiology. 1960 Mar-Apr;21:153-8.

2. Howie MB, Hiestand DC, Zvara DA, Kim PY, McSweeney TD, Coffman JA. Defining the dose range for esmolol used in electroconvulsive therapy hemodynamic attenuation. Anesth Analg. 1992 Nov;75(5):805-10.

3. Korenaga, GM Kirkpatrick A, Lord JC, Barabas E Effect of Esmolol on tachycardia induced by Endotracheal intubation Anesth Analg 1985; 64: 185304.

4. Charles S. Reilly M.D., Margaret Wood M.D., Koshakj Phd. and Alastair J.J. Wood, M.D. Ultra short acting beta blockade. A comparison with conventional beta-blockade. Sheffield U.K. (1985)

5. Withington DE, Ramsay JG, Ralley FE et al. Attenuation of the hemodynamic response to intubation by bolus doses of esmolol. In Society of Cardiovascular Anaesthesiologists, 1988. 
6. Parnass S, Rothenberg D, Kerchberger J, Ivonkovich A. Single dose Esmolol for prevention of hemodynamic changes of intubation in an ambulatory surgery unit. Anaesthesiology 1989, 71: A12.

7. Vucevic M, Purdy GM, Ellis FR. Esmolol hydrochloride for management of the cardiovascular stress responses to laryngoscopy and tracheal intubation. Br J Anaesth. 1992 May;68(5):529-30.
8. Sheppard S, Eagle CJ, Strunin L. A bolus dose of esmolol attenuates tachycardia and hypertension after tracheal intubation. Can J Anaesth. 1990 Mar;37(2):202-5.

9. Joshi SR, Jain PK - Esmolol - New novel Ultrashort acting p -blocker. The Indian Practitioner Aug. 1997, Vol.50, No.8,: 717-727.

\section{How to cite this article?}

Tamaskar A, Bhargava S, Rao M, Bhargava S, Singh M. Effect of Esmolol hydrochloride on attenuation of stress response during laryngoscopy and intubation in ear, nose and throat (ENT) procedures. Int J Med Res Rev 2015;3(11):1370-1377. doi: 10.17511/ijmrr.2015.i11.248. 